\title{
LOST IN THE CLOUD - NEW CHALLENGES FOR TEACHING GIS
}

\author{
C. J. Bellman* and G. Pupedis \\ Dept. of Geospatial Science, School of Science, RMIT University, Melbourne, Australia \\ (Chris.bellman; Gita.Pupedis)@rmit.edu.au \\ Commission VI, WG VI/2
}

KEY WORDS: Cloud based GIS, open source, open data, teaching and learning

\begin{abstract}
:
As cloud based services move towards becoming the dominant paradigm in many areas of information technology, GIS has also moved into 'the Cloud', creating a new opportunities for professionals and students alike, while at the same time presenting a range of new challenges and opportunities for GIS educators. Learning for many students in the geospatial science disciplines has been based on desktop software for GIS, building their skills from basic data handling and manipulation to advanced spatial analysis and database storage. Cloud-based systems challenge this paradigm in many ways, with some of the skills being replaced by clever and capable software tools, while the ubiquitous nature of the computing environment offers access and processing from anywhere, on any device.
\end{abstract}

This paper describes our experiences over the past two years in developing and delivering a new course incorporating cloud based technologies for GIS and illustrates the many benefits and pitfalls of a cloud based approach to teaching. Throughout the course, students were encouraged to provide regular feedback on the course through the use of online journals. This allowed students to critique the approach to teaching, the learning materials available and to describe their own level of comfort and engagement with the material in an honest and non-confrontational manner. Many of the students did not have a strong information technology background and the journals provided great insight into the views of the students and the challenges they faced in mastering this technology.

\section{INTRODUCTION}

Existing courseware in Geospatial Science equips students with a sound knowledge of geospatial science theory and methods and develops strong skills in range of software packages. However, geospatial technologies are rapidly moving to cloudbased solutions and service offerings (Muzafar et. al. 2011), often coupled with open source software solutions to geospatial science problems. This is seen as the next natural step in the evolution of information technology services and products. Sui (2014) suggests we are moving to a new era of open GIS, inspired by the open source community and also by the shift in sentiment of governments toward open data, culminating in the signing of the Open Data Charter at the 2013 G8 conference (Eaves 2013). Despite this enthusiasm for open systems, only a few university curricula include open source for GIS (Mitasova et. al 2012), with most still relying on proprietary software. While this is possibly driven by industry demand for skills in particular software systems, there is growing support for open source GIS (Belgui et. al. 2015).

This paper describes our experiences in developing and implementing a new course that sought to extend the skills and knowledge of geospatial science students by introducing cloudbased and open source solutions for GIS. The changes in courseware were a direct response to industry demand for graduates with greater understanding and knowledge of cloudbased and open source geospatial solutions, and the capability to adopt innovative methods to solve emerging problems.

The course development began as a project funded through an internal Learning and Teaching Fund grant. The aims of the project were to:
- Provide opportunities for geospatial students to work with open source and cloud-based technology on industry problems

- Expose students to the range and capabilities of cloud-based services in geospatial science through the creation of a sandbox

- Provide opportunities for students to work alongside industry personnel in creating solutions to current industry issues

- Further engage industry practitioners in the geospatial discipline at RMIT

These goals closely aligned with RMIT University's Academic Plan 2011 - 2015 (RMIT,2011), which had a strong emphasis on producing work ready graduates and improving engagement with industry.

\section{COURSE DESIGN AND STRUCTURE}

\subsection{Design issues}

The course is part of a broad program in the geospatial sciences and is delivered towards the end of a sequence of courses in Geospatial Information Science (GIS). As a result, many students had a good understanding of GIS concepts and a sound knowledge of proprietary GIS software.

One of the goals of the course was to expose students to different systems and technologies such as open source systems and cloud services for GIS.

The project originally conceived the construction of a geospatial "sandbox" in the cloud - a virtual 'place' offering students the 
opportunity to learn by discovering solutions to problems based on industry case studies. The reality was somewhat different and rather than a holistic and central 'place', we created a disparate but connected environment, where students could work in a virtual or real computer environment, using open source software and tools or web and cloud based technologies, in response to their needs and interests.

Originally, we had conceived using a cloud service such as Amazon Elastic Compute Cloud (EC2) to provide an independent and customisable computing platform for open source applications. This proved to be more difficult than anticipated from inside the university firewalls and for some students, beyond realistic expectations of their technical ability. Fortunately, the university had recently launched its own virtual computing environment and provided a tool (MyCloud) to create and manage virtual machines (VMs) from within the university firewall and security systems. While these VMs were not scalable nor particularly powerful from a processing perspective, they were simple to create and had sufficient storage capacity for the exercises in this course. The use of virtual machines overcame the many problems of corporate IT structures, rules and security, allowing students to gain some experience in technical aspects of GIS-based IT operations, such as installing open source software and the database administration tasks involved in creating and managing spatial databases.

An important aspect of the course was the desire to have contextually relevant and realistic case studies for the students to work on in their practical work. The case studies and suitable approaches to their solution were developed through workshops and discussions with industry participants, who were very keen to support the development of these skills in students. In many cases, the students downloaded data from open data sources and had to massage and manipulate this data to suit the task at hand. This gave the students a great sense that they were using real data and therefore the exercises were not simply academic tasks but had some basis in reality.

\subsection{Course Structure}

The course is delivered as a semester long course over twelve weeks and is aimed at students in the third year of a four year undergraduate program and students enrolled in a coursework Masters program. The lecture and practical sessions are tightly coupled, with the practical sessions occurring immediately after the lectures. This was particularly suitable for the postgraduate students, many of whom worked full time and this provided a structure that minimised their time away from work.

Table 1 show an outline of the topics covered and the corresponding practical activities.

\begin{tabular}{|c|c|c|}
\hline Week & Lecture & Practical \\
\hline 1 & $\begin{array}{l}\text { Course Introduction } \\
\text { Survey of student } \\
\text { knowledge } \\
\text { Glossary of terms } \\
\text { Discovery exercise }\end{array}$ & $\begin{array}{l}\text { Building virtual } \\
\text { machines }\end{array}$ \\
\hline 2 & $\begin{array}{l}\text { Q\&A on Discovery } \\
\text { Exercise } \\
\text { Introduction to open source } \\
\text { systems and QGIS/PostGIS }\end{array}$ & $\begin{array}{l}\text { Open Geo } \\
\text { /QGIS/PostGIS; } \\
\text { QGIS exercise }\end{array}$ \\
\hline 3 & $\begin{array}{l}\text { Cloud-based systems, } \\
\text { services and connections }\end{array}$ & $\begin{array}{l}\text { QGIS exercise } \\
\text { (cont.) }\end{array}$ \\
\hline 4 & $\begin{array}{l}\text { Introduction to Carto DB } \\
\text { Industry lecture - Open } \\
\text { source issues }\end{array}$ & $\begin{array}{l}\text { CartoDB for map } \\
\text { making and analysis }\end{array}$ \\
\hline 5 & $\begin{array}{l}\text { Introduction to ArcGIS } \\
\text { Online } \\
\text { Discussion of project } \\
\text { parameters }\end{array}$ & $\begin{array}{l}\text { ArcGIS Online map } \\
\text { making } \\
\text { Project scoping } \\
\text { exercise }\end{array}$ \\
\hline 6 & $\begin{array}{l}\text { Open data movement and } \\
\text { policies } \\
\text { Open standards for GIS }\end{array}$ & $\begin{array}{l}\text { Open Street Map } \\
\text { and other open data } \\
\text { discovery (eg. } \\
\text { data.vic.gov.au) } \\
\text { Project scoping } \\
\text { discussion/feedback }\end{array}$ \\
\hline & Semester break & \\
\hline 7 & $\begin{array}{l}\text { Briefing on readings for } \\
\text { database \& server } \\
\text { approaches/systems }\end{array}$ & $\begin{array}{l}\text { Project proposals } \\
\text { due }\end{array}$ \\
\hline 8 & $\begin{array}{l}\text { Industry lecture - map tiling } \\
\text { and optimisation } \\
\text { Industry feedback on } \\
\text { project proposals }\end{array}$ & Using Tile Mill \\
\hline 9 & Serving Up Maps & $\begin{array}{l}\text { Publishing data } \\
\text { with Geoserver } \\
\text { Project drop-in } \\
\text { session } \\
\text { (Industry support) }\end{array}$ \\
\hline 10 & Database/server issues & $\begin{array}{l}\text { Project drop-in } \\
\text { session } \\
\text { (Industry support) }\end{array}$ \\
\hline 11 & $\begin{aligned} & \text { Reflection on cloud service } \\
& \text { issues } \\
& \text { - } \text { compromises } \\
& \text { - } \text { security } \\
& \text { - } \text { sovereignty }\end{aligned}$ & $\begin{array}{l}\text { Project drop-in } \\
\text { session } \\
\text { (Industry support) }\end{array}$ \\
\hline 12 & $\begin{array}{l}\text { Project demos } \\
\text { Review and evaluation of } \\
\text { course }\end{array}$ & $\begin{array}{l}\text { Project submission } \\
\text { (Industry review) }\end{array}$ \\
\hline 13 & $\begin{array}{l}\text { Journal submission/class } \\
\text { test }\end{array}$ & \\
\hline
\end{tabular}

Table 1 - Week by week course structure.

\section{IMPLEMENTATION}

As can be seen from the course structure in Table 1, the early part of the course enables students to explore open source software services such as QGIS, PostGIS, Geoserver, TillMill 
and cloud-based GIS systems such as CartoDB and ArcGIS Online, and to trial their solutions to the problems given. This structure is similar to many other advanced level GIS courses (Mitasova et.al. 2012; Petras et.al. 2015)

While there is a rich and growing pool of software and services available for GIS (Fu \& Sun, 2011; Muzafar et. al., 2011), these systems were chosen in consultation with industry as good representative examples of systems in each category and all had the advantage of being available without cost to students or, in the case of ArcGIS Online, through an existing university software license.

To develop the necessary skills, students were immersed (lost) in the cloud and had to find solutions to the problems that arose. While conventional lectures were employed to explain the principles and context of applications, systems and services, the course was structured as a problem-based learning environment, allowing students to develop and experiment with solutions, make mistakes and even break things. Students were provided with a structured learning task for each application, which was completed in the practical class and then given a challenge task to complete in their own time. These challenge tasks contributed to the final assessment. Some students found this approach quite challenging and a little frustrating. However, feedback from the students towards the end of the course was extremely positive and most claimed they valued the learning experience and now felt more comfortable with the new technologies. As most of the services were internet and cloud based or could be run on a virtual machine, students were able to engage in these exercises without the constraints of corporate IT structures.

The final stage of the course was a capstone assessment task, where students designed their own project, with the only rules being that they must use cloud based or open source technologies, they must use open data and that they would be rewarded for taking risks and being adventurous in their approach. To complete the project, students must find their own data to analyse and map, choose an appropriate open source or cloud-based technology to manipulate and display the data and deliver a presentation of the result to an audience of their peers and industry representatives. Many students embraced this challenge and produced products and services that were outstanding, while others were a little over-awed by the freedom they had been given and required significant coaching to produce a product of the required standard. In several cases, students built a complete GIS data system in the cloud, based on QGIS and/or PostGIS and hosted on an Amazon EC2 Web Service.

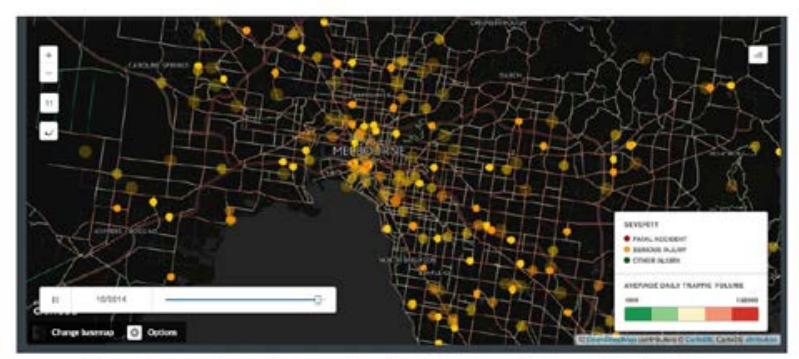

Map 1. Torque Visualisation of Crash Statistics and Average Traffic Volumes

Figure 1 An example of student final project
An example of student project work is shown in Figure 1. The map was created from open data on vehicle crashes published by Victorian State Government through its open data portal, integrated with road network data from Open Street Map and displayed using the Torque visualisation function in CartoDB (CartoDB Torque 2013).

\section{LESSONS}

Students entering the course came from diverse backgrounds. Some students had a sound background in geospatial science, a good understanding the concepts and some familiarity with proprietary software systems. Other students came from backgrounds with limited exposure to geospatial science and may have only completed introductory courses in GIS. Typically, these students come from backgrounds in planning or environmental science and were attracted to the course by the potential for the application of geospatial science principles to their own discipline. In general, while most students were competent users of IT systems, they had a very limited understanding of how IT systems operate and the components that allow these systems to function effectively. This was not universally true, as some students had very strong IT backgrounds, including some with qualifications in computer science. Many students were also largely unaware of cloudbased systems, even though they were using them on a daily basis.

\subsection{Personal Response Systems}

The course made extensive use of personal response systems (sometimes known as 'clickers') in the lectures. There is much evidence to suggest that these systems create a far more interactive environment for students and promote much deeper thinking about the topics presented (Moss \& Crowley, 2011). Our experience and the feedback received from students strongly support this view. The 'clickers' also provided instant feedback to the academic staff about student understanding of the topics presented, allowing adaptive responses to reinforce the information that had been presented or the surety to move on to new topics with confidence that the previous topics were well understood.

\subsection{Software stability/versioning}

One key issue that emerged from the perspective of academic delivery and sustainability was the stability of the software environment. The open source systems were regularly updated and it was difficult to control which version of the software students downloaded and installed. Despite explicit instructions about versions, invariably some students were working with versions of the software that were different to the majority of the class. This caused occasional problems in completing some tasks and the provision of support for a range of software versions was much more difficult. As students were encouraged to use their own computers, the issue of software versions was also compounded by the variety of operating systems installed on their computers.

Of more concern were updates to the cloud-based systems. These could occur without notice and on more than one occasion, instructions for practical classes had to be re-written at short notice due to significant changes to the cloud software interface. Changes to software installed on a user's computer are made largely at the user's discretion and updates can be planned and controlled to suit work requirements and demands. 
This paradigm changes with cloud-based services, as software updates happen at the discretion of the service provider and can occur without notice. This is particularly problematic when substantial changes are made to the user interface or the operational mode.

\subsection{Network overheads}

The use of virtual machines and cloud-based services exposed an unexpected vulnerability in the form of network and internet overheads. Operating these systems and services from inside university firewalls led to highly variable response times and in some cases, poor performance of the application software. These problems were intermittent and difficult to replicate. They appeared to be a function of local demand on the network and internal network bandwidth limitations but could also be caused by excessive demand on the cloud service.

\section{STUDENT FEEDBACK AND EVALUATION}

\subsection{Discussion boards}

Students were encouraged to contribute to online discussion boards and journals for the class. The discussion boards were open and visible to the whole class, whereas the journals were private communications only visible to the academic staff running the course.

The discussion boards were very useful in the early stages of the course, as topics could be raised and ideas or opinions shared in an open and collaborative manner. The discussion boards created a community learning environment where students were encouraged to find sources of information and share this with the class. These were also moderated discussions, so academic staff could intervene at any time and steer the conversation back onto topic or pose new, alternative or controversial questions for consideration. While some marks were allocated to participation in the discussion boards, most students seemed to participate through a genuine desire to understand the topic more fully. As the semester progressed and students' understanding and knowledge grew, the value of the discussion boards diminished, in part because the students became more focussed on their own projects and less interested in discourse.

\subsection{Reflective Journals}

The reflective journals were a different matter. There were no specific rules associated with the journal, beyond keeping all submissions professional and respectful. Students were encouraged to enter their thoughts as they occurred. As private communications with the academic staff delivering the course, students could give opinions that were not visible to or open to interpretation by other students. Some students were reluctant to contribute to the journal and only did so because the journal provided some credit towards their final grade. These students often posted quite innocuous comments, such as "I liked that class" or "I found this topic boring”. However, other students relished the opportunity to give their opinion on the structure and pace of the course, the relevance of the topics, the quality of the lecture material/delivery or the practical class. These comments were far more revealing than expected and at times, extremely frank and forthright. This required some robustness on behalf of the academic staff. One student went so far as to score each class in terms on delivery, content and impact. However, the comments provided great insight into the thinking of the students at a particular point of time during the course. A common theme in the feedback from the students was their appreciation of the industry involvement in the course and the relevance of the exercises. Some students, particularly those from other disciplines, found the focus on technical IT issues was greater than required for their needs.

Students were encouraged to complete their journal entries on a weekly basis, as soon as possible after the class. This allowed academic staff to gauge whether students felt comfortable with the material and the exercises or were feeling overwhelmed (or underwhelmed) and frustrated. The content, pace of delivery, emphasis and review sessions could then be modified to the needs of the class more effectively.

\section{CONCLUSION}

The opportunities presented by open source and cloud based systems and services open up a range of possibilities for the teaching of GIS. These opportunities extend from tools that support simple integration of data into spatial visualisations to complex IT infrastructures built using open source software and database systems on cloud computing platforms. In doing this, the challenges are many and the demands placed on academic staff to keep the material up to date and understandable to students from a variety of backgrounds and technical abilities is considerable.

The course development project described in this paper drew on real case studies provided by industry to create a geospatial "sandbox" in the cloud, offering students the opportunity to learn by discovery and develop the necessary skills and techniques to solve the problems posed by the case studies. Industry participants worked closely with staff and students on the case studies and provided feedback to students on their work. This provided an excellent learning framework for students.

The project provided an outstanding opportunity to extend current geospatial science teaching approaches and offer learning experiences that immersed students in the cloud and allowed them to undertake deep learning activities anytime/anywhere with a simple internet connection. At the same time, the project demonstrated clearly that RMIT University is responsive to the needs of industry and continues to focus on developing work-ready graduates.

\section{ACKNOWLEDGEMENTS}

The authors would like to acknowledge the strong support received from Mr Craig Molyneux from Spatial Vision Pty.Ltd as the key industry advisor and as developer of many of the learning materials and industry case studies. Without his help and the support of his colleagues at Spatial Vision, many aspects of the course would not have been possible.

Dr. Barbara Rasaiah's role as research assistant, sounding board, chief critic and key tester of all practical tasks ensured the learning materials were of a high standard and accessible and understandable to students. She also performed an invaluable role as learning advisor to many students in both formal and informal sessions.

The support of RMIT University through its Learning and Teaching Investment Fund is also gratefully acknowledged. 
Without this, the new course design would not have been possible.

\section{REFERENCES}

Belgiu, M. Strobl, J., and Wallentin, G., 2015, Open Geospatial Education, ISPRS International Journal of Geo-Information. 2015, Vol 4, 697-710.

CartoDB Torque (2013) http://blog.cartodb.com/torque-is-livetry-it-on-your-cartodb-maps-today/ (April 15, 2016).

Eaves, D, 2013, Open Data Goes Mainstream with G8 Charter., http://techpresident.com/news/wegov/24096/open-data-goesmainstream-g8-charter (25 March, 2016).

Fu, P. \& Sun, J., 2011, Web GIS - Principles and Applications, ESRI Press, Redlands, California.

Mitasova, H., Landa, M. and Shukunobe, M., 2012, Building open source geospatial education at research universities: Where we are and what is holding us back. In: Proceedings of the 2012 Open Source Geospatial Research \& Education Symposium, Yverdon-les-Bains, Switzerland,24-26 October 2012.

Moss, K. and Crowley, M., 2011, Effective learning in science: The use of personal response systems with a wide range of audiences Computers \& Education, Volume 56, Issue 1, January 2011, Pages 36-43.

Muzafar, A. B., Razeef M. S., and Bashir, A., 2011, Cloud Computing: A solution to Geographical Information Systems (GIS), International Journal on Computer Science and Engineering, 2011, Vol.3(2), p.594.

Petras, V., Petrasova, A., Brendan Harmon, B., Meentemeyer, R.K., and Mitasova, H., 2105 Integrating Free and Open Source Solutions into Geospatial Science Education. ISPRS International Journal of Geo-Information. Vol 4, 942-956.

RMIT Academic Plan 2011-2015,

http://mams.rmit.edu.au/7ubueffp958h.pdf, (April 15 2016).

Sui, D., 2014, Opportunities and Impediments for Open GIS, Transactions in GIS, Vol 18(1): 1-24. 